\title{
THE PRESENT STATUS OF LEPROSY IN THE HAWAIIAN ISLANDS*
}

\author{
WILLIAM THOMAS CORLETT, M.D., L.R.C.P. (LOND.) \\ Senior Professor of Dermatology and Syphilology, \\ Western Reserve University \\ CLEVELAND
}

By some, leprosy is supposed to have been introduced into the Hawaiian Islands by the Chinese, many of whom settled there about the middle of the nineteenth century. The reason for this belief rests on the fact that the first name by which the disease as a distinct entity was known in the Islands was mai pake, meaning Chinese disease.

Wayson ${ }^{1}$ and other leprologists who have lived long on the Islands, as well as others who have recorded earlier observations, do not share this view, but believe that the disease has existed from a more remote period and was probably introduced by sailors or the roving inhabitants of the islands of the South Seas, where from the earliest times it has been endemic. The missionaries who came here in 1820 reported that some of the natives were afflicted with what they called scrofula, "which was not only frequently met with but extremely malignant.” 2

\section{LEPER HOSPITAL AND SETTLEMENT}

Soon after the middle of the last century, however, leprosy had made such headway among the native population that in $1865 \mathrm{King}$ Kalakaua called a council to consider means of checking its spread. Segregation of those afflicted and treatment with chaulmoogra oil seemed to offer the most promising means of relief. Accordingly, a hospital for the examination and treatment of persons affected with leprosy was established in November of the same year. It has been in almost continuous existence ever since and is now known as the Kalihi Observation and Detention Hospital. This hospital is situated in the suburbs of Honolulu and consists of a number of small frame buildings pleasantly situated in an inclosure of several acres.

In addition to this hospital, in which it was intended that patients presenting incipient manifestations of the disease and others thought amenable to treatment might be detained, there was established a leper settlement on the island of Molokai, about 80 miles (128 kilometers)

* Read at the Forty-Fifth Annual Meeting of the American Dermatological Association, Washington, D. C., May 2-4, 1922.

1. Wayson, J. T.: N. Y. Med. Rec., November, 1904.

2. Report of the board of health to the legislative assembly of 1886 . 
distant from the island of Oahu and Honolulu, the capital of the island group, known as the Kalaupapa Leper Colony. This is situated on a tongue of land 8 square miles (20 square kilometers) in area, projecting into the sea from the north side of the island of Molokai and walled in by the Kalaupapa, a precipitous mountain range or pali, 2,000 feet (600 meters) in height, which affords a natural barrier against escape, as well as complete isolation.

The first consignment of patients arrived at this segregation colony in January, 1866. During the first ten years, 1,587 lepers, who should rightly be called patients, were received.

During this decade, the largest number was received in the year 1873, when 487 lepers were consigned to Molokai; while in 1886 there were only forty-three, this being the smallest number received in any single year during this period. An equal variability in the number of patients domiciled at Molokai at different times is also noted. Thus in 1890 there were 1,213 ; while in 1886 , the end of the first decade, there were only 590 .

\section{POLICIES IN DEALING WITII THE DISEASE}

This irregularity has continued to the present time, on account of variations in policy in dealing with the disease, which governmental changes have engendered, and bears no relation to the actual number of lepers on the Islands, which, in proportion to the number of inhabitants, has of late slightly decreased.

Mouritz, ${ }^{3}$ in his treatise on leprosy in the Hawaiian Islands, speaks thus of this phase of the local situation: "The segregation of lepers has been irregular, spasmodic, and efficient only at certain periods. This is only too plainly evident in the testimony supplied by the yearly number of lepers segregated, as per the following figures, which indicate activity and slackness, alternately; depending in the main on election and non-election years." Then follows the yearly consignments from 1866 to 1899 , which varied from 43 to 571 (1888). He continues: "The efforts to stamp out leprosy by segregation have taken on the status of a political football, the party in power being assailed by the outs, who return the attack in kind. Both parties have been offenders, using the care and segregation of lepers as a target or a cudgel, depending on the state of the case. The Hawaiians have the majority of votes, and to placate voters and gain their votes the enforcement of the segregation law has been purposely allowed to lapse temporarily." He then makes a plea for federal control, which has since been partially accomplished.

3. Mouritz, A. A. St. M.: The Path of the Destroyer; a History of Leprosy in the Hawaiian Islands, Honolulu, 1916, pp. 165-166. 
This shifting policy in dealing with the problem of leprosy, or rather in looking the problem squarely in the face, is also influenced by commercial and social interests. The unwholesome reputation the Hawaiian Islands received in the death of Father Damien in 1889, and the wide publicity it was given, created in the minds of most people a feeling of dread, even of repugnance whenever the Hawaiian Islands were mentioned. This was not warranted by the facts, and to counteract this wrong impression measures tending to the opposite extreme have been from time to time resorted to. This has resulted in the conflicting reports and the consequent uncertainty that exists in the minds of medical men as to the actual status of the leprosy problem in the Hawaiian Islands.

\section{ESTABLISHMENT OF U. S. CONTROL}

Soon after the United States took over the Islands as a territory, the Marine Hospital and Public Health Service was asked to take charge of the leper problem. A cooperative plan was devised in which the department of public health works in connection with the local board of health. But the national control of leprosy has not yet accomplished the desired result, that of taking the most efficient measures for controlling the disease.

An attempt was made with, I am told, an expencliture of about $\$ 250,000$ for buildings and other equipment, including an ice plant and even microscopes, on the island of Molokai. But here again a change in national policy or procedure took place, and the buildings, which have never been occupied, lie rotting, and the other partial equipment remains corroding and unused. In fact, after a lapse of ten or twelve years no benefit has ever accrued from this somewhat ambitious though abortive attempt to study the subject of leprosy and to employ the most efficient means of controlling this widespread disease, which by some is regarded not only as a local, but also as a national, menace.

TREATMENT BY CHAULMOOGRA OIL

The announcement in 1904 that Power ${ }^{4}$ and his collaborators in the Welfare Research Laboratory had succeeded in separating certain fatty acids from chaulmoogra oil led many too enthusiastic leprologists to affirm that if the actual cure of leprosy had not been attained its ultimate eradication from the face of the globe was in sight.

Taub further elaborated the separation of the ethyl esters from chaulmoogra oil, and after their extensive use, particularly in Turkey and Egypt, in the treatment of leprosy, the process was patented in the

4. Power and Gornall: J. Am. Chem. Soc. 85:838, 851, 1904. Power and Barrowcliff: ibid. 87:884, 1905. Barrowcliff and Power: ibid. 91:557, 1907. 
United States in 1910, under the trade name antileprol. ${ }^{5}$ In these letters patent, full and explicit directions are given for the elaboration of the ethyl esters from chaulmoogra oil as used today in the Kalihi Hospital and Station, as well as at the colony of Kalaupapa on the island of Molokai. The ethyl esters in the form of antileprol were previously used in the Kalihi Hospital at Honolulu by Wayson, between 1910 and $1914,{ }^{6}$ with about the same results as Rogers in India and others were obtaining.

Heretofore, chaulmoogra oil and its derivatives had been given by the mouth. It was disagreeable to the taste and often its use had to be abandoned on account of the deleterious effect on the patient. In 1914, Heiser ${ }^{7}$ advocated the use of chaulmoogra oil diluted with an equal quantity of camphorated oil, with $4 \mathrm{gm}$. of resorcin to every 120 c.c. of the mixture. This was given intramuscularly with encouraging results.

During the World War, letters patent were apparently not considered any more seriously than were other scraps of paper when public necessity required their infraction ; consequently Dean, ${ }^{8}$ of the University of Hawaii, in 1919, separated the ethyl esters from the crude chaulmoogra oil, as Taub had previously done, and McDonald, ${ }^{8}$ and later Wellman, administered them intramuscularly at the Kalihi Hospital. The enthusiasm with which this treatment was received and entered into seems to have been in inverse ratio to the permanent benefit derived. Improvement undoubtedly took place in many cases, especially in the early or mild forms of the disease.

\section{PAROLE OF PATIENTS}

Although more or less painful, the discomfort was confined to the buttocks, and patients were able to receive more of the active elements of the drug than they had previously been able to receive by way of the mouth, and with less disturbance to their general health. Consequently, the enthusiasm was not confined to the hospital staff, but was participated in by the afflicted, who saw in this treatment a brighter prospect of being returned to their homes restored to health. Between July 9, 1919 and March 31, 1921, 140 patients were paroled from the Kalihi Hospital as either cured or no longer a menace to the community at large; thus, a semblance of reality was given to this bright outlook.

5. U. S. Patent No. 957633, May 10, 1910, Washington, D. C.

6. Report of Hawaiian Board of Health, 1912; also personal communication to the author.

7. Heiser, Public Health Reports 29:2763, No. 42.

8. McDonald, I. T., and Dean, A. L.: The Treatment of Leprosy, Pul). Health Rep. 35:1959 (Aug. 20) 1920; The Constituents of Chaulmoogra Oil Effective in Leprosy, J. A. M. A. 76:1471 (May 28) 1921. 
During this period, sixty patients were discharged from the leper settlement at Molokai. Of this large number, sixteen have since been returned to the Kalihi Hospital, six have died while on parole, one is known to have escaped from the Islands, and only two have been released from parole as apparently cured, and these prior to the end of the four year period (in which no symptoms of leprosy have appeared, the patient remaining during this time bacteriologically negative) now thought necessary. This still leaves 115 paroled patients from the Kalihi Hospital unaccounted for, as well as those from Molokai.

Two of these paroled patients deserve more than a passing notice. One was a woman of uncertain repute who. on being paroled, entered one of the houses of prostitution in Honolulu, where, after the most intimate exposure of her patrons, who are said to have included soldiers from all parts of the United States, she was finally apprehended as a leper having the disease in its active stage. She is now under treatment at the Kalihi Detention Hospital.

The second patient, also a woman much in the public eye, was discharged from the Kalihi Hospital as cured during the large exodus of 1919, which accompanied the announcement to the world that leprosy was at last completely amenalle to treatment. She was exhilited at public gatherings as an example of a cured case of leprosy, and, I am told by eye witnesses, kissed as one "snatched from the jaws of death." This took place during the meeting in Honolulu of the American Press Association and elicited expressions which I will quote from a recent number of what I had considered a conservative weekly publication. "Miss R. B., an Hawaiian woman, had been a leper and was pronounced cured. . . . Miss B., after long treatment at Kalihi, had been among fifty selected to pass across the dark waters of the channels to Molokai-incurable. At the eleventh hour, however, Dr.

saw that she was responding to the Dean treatment." The first to be pronounced cured and safe to resume her place among her fellowmen. She is cured."

Again, from a local editorial ${ }^{10}$ published during the Press Association meeting :

\section{HONOLULU'S MOLOKAI}

The patient who has had leprosy and has been cured may be shy a finger joint, or the tip of an ear, but before God and man he is as clean and free of the disease as a man who has had a carluncle lanced and has got over it. Hawaii's conquest of leprosy is the greatest achievement of the many of which this land boasts. We not only ask, we urge you to go to Kalihi Hospital today and see this greatest marvel for yourselves, then pass on the wordHarcaii has cured its lepers."

In this star case of "cured leprosy," which was given as much publicity as was the life work and death of Father Damien, who, by the

9. Names given in original article. Leslie's, July 30, 1921.

10. Pacific Commercial Advertiser, November. 1921. 
way, was only one of three priests who have died of leprosy in these islands, the patient was returned to Kalihi Hospital a few months later with the disease under full headway, where I had an opportunity repeatedly to observe the case.

During my stay in the islands, I took occasion to examine a few of the many paroled patients who had either discontinued reporting weekly at the Kalihi Hospital as they are required to do, or had never reported since being released on parole. In one instance, a mother and two children had been paroled. One child, although never having presented any symptoms of leprosy, had been hospitalized with the mother and sister, who were lepers. The mother was now bedridden in her home from active manifestations of the disease, and the affected child also presented macular lesions on the skin, with partial paralysis of one eyelid. One child still remained free from symptoms. Both children were attending school. Neither the mother nor the affected child were reporting at the hospital. Their dwelling was in the center of a large taro plantation which furnishes one of the principal articles of food, poi, of the Islands.

Three other paroled patients who were not reporting at the hospital were following their various vocations, one a flower vendor, one a city employee and one a student. While presenting leprous stigmas, the disease, so far as I could ascertain, was not in an active stage. Whether or not these quiescent or mild forms are a menace to the public health, from our present knowledge of the disease we are unable to say.

\section{SURVEILLANCE OF PERSONS AT LARGE}

Koch, during his visit here, it is said, obtained lepra bacilli from the nasal mucosa in some of these apparently inactive cases. Two other persons who were not under surveillance of the board of health came under my observation. One was a teacher in one of the public schools and the other was the elevator boy whom I had the opportunity of repeatedly though somewhat furtively examining throughout my stay. In both, there were visible evidences of implication of the facial and ulnar nerves, with consequent paralysis and atrophy of the levator labii and the adductor pollicis and first dorsal interosseus muscles of the face and hands, respectively.

Granting these were mild or incipient cases of leprosy, with our present lack of exact knowledge as to the mode of transmitting or acquiring the disease, we are unable to say whether or not they are a menace to the public health. Here, it is undoubtedly better to err on the side of safety.

In going through one of the large pineapple canneries in Honolulu, I was impressed with the neatness with which the process was accom- 
plished, and to see the sealed cans finally passing through a steam sterilizer. This, with the wearing of rubber gloves by those who handled the fruit, was especially comforting to me later, on hearing that three employees had previously been afflicted with leprosy. Since which time, all employees of this particular cannery are examined by a member of the board of health once a month.

On the other hand, from what $I$ saw, it is my belief that there are fewer persons at large afflicted with leprosy in the Hawaiian Islands than in most other countries I have seen where the disease prevails to the same extent. This is due, I believe, to the efficient services rendered by Dr. F. E. Trotter, president and officer of the board of health; Dr. James $T$. Wayson, the leprologist, member of the board of health and former health officer, and Dr. H. E. Hasseltine, of the U. S. Public Health Service, medical officer in charge of the Kalihi Hospital. At the present time, as for the last three years, all cases of leprosy occurring on the Islands are sent to the observation and detention hospital at Honolulu, where they are paroled or detained, as seems best. In mild cases, the patients returning to receive their weekly treatment are permitted to live at home. There are detained at the present time 187 patients. They are comfortably housed in small wooden buildings, with additional structures for schools, cooking and eating.

Since about the middle of 1921 , the treatment consists of weekly injections of all the ethyl esters of chaulmoogra.oil, the attempt to isolate any particular acid having given less promising results. The medicament is prepared at the chemical laboratory of the University of Hawaii from the crude oil, which is imported from India. From 1 to 6 c.c., varying according to the weight and condition of the patient, are injected into the gluteal muscle. During the last few months, the ethyl esters have been given intravenously to a selected number of patients in 1 c.c. doses, twice or thrice weekly. The ethyl esters in capsule are also given by mouth in some cases. Iodin, which was formerly given in the proportion of 2.5 per cent., is now discontinued.

At Kalaupapa, on the island of Molokai, of the sixty patients paroled during the period between 1919 and 1921, there are recorded eleven relapses, and two who died on parole. The fate of the remaining forty-seven is unknown.

The treatment carried out by Dr. W. J. Goodhue, resident physician at this colony, is said to be that followed at the Kalihi Hospital. The treatment here, however, is not compulsory. Since the leper colony occupies but a small part of the Island of Molokai, and is shut off from the rest of the island, there is apparently an effort to lift the onus of leprosy from Molokai. This, with the almost complete isolation of the 
colony, has evidently led to the abandonment of Molokai as a haven to which all lepers are sent. No cases of leprosy are admitted to these islands from other parts of the United States.

\section{UNSOLVED PROBLEMS}

Since the disease became recognized as a public menace, efforts have been made to ascertain its mode of propagation, the influences which favor such dissemination and the best treatment. Distinguished scientists, among whom may be mentioned Koch and Arning, have studied the disease $i n$ loco, and still the two major problems, those of dissemination and cure, remain unsolved.

\section{CONCLUSIONS}

Leprosy was probably introduced into the Hawaiian Islands from without, some time during the last century. The disease spreads rapidly among the Hawaiians because of their intimate mode of living, together with their laisscz fairc attitude in regard to the disease. With this, complete segregation is difficult of accomplishment.

It is most prevalent during school age. It is most common in the male sex. A specific for leprosy has not yet been fully attained.

If one might be permitted to make a few suggestions on impressions gained from a study extending over only a few weeks they would be :

A more definite plan of procedure should be established. If the changing conditions consequent on our elective form of government are allowed to continue to influence the work, it would seem better that it be assumed by a nonpolitical body, such, for example, as the Rockefeller Foundation could furnish.

If the present system continues, there should be, in addition to Dr. H. E. Hasseltine, the efficient medical officer of the Public Health Service now cloing all the work of the Kalihi Hospital, a trained clinician, or at least some one appointed or detailed by the Public Health Service, in place of the more inclefinite and heterogenous board of health. Not that there is wanting local ability amply to fill this important position if subjected to a nonpartisan, nonlocalized body.

Then, in addition, there should be sent to this field a research worker of undoubted ability-one of the few who like poets are born and not made-to ascertain, first of all, how the disease is acquired. This, in my opinion, is the first great problem to be solved. Its prevention would then be clear; its treatment is already being elucidated and improved. This position should be untrammeled by local influences, and its incumbent should be given a free hand.

Finally, the ethyl esters of chaulmoogra oil undoubtedly have a beneficial effect on most cases of leprosy; in some, it apparently does 
harm by aggravating the disease; while in mild or early cases, it apparently, for a time at least, arrests the progress of the disease.

\section{DISCUSSION}

Dr. Grorgf Hranry Fox, New York: I have been greatly interested in the paper of Dr. Corlett. Some twenty-five or thirty years ago it was my privilege to see and treat a large number of cases of leprosy in New York, all of which were imported cases. I remember using Hoang-nan, a Chinese drug, from which I do not remember obtaining great benefit. I remember giving doses of strychnia without any result, but chaulmoogra oil was, in my opinion, then and now a most valuable remedy. Nearly all of the patients that I treated with large or small doses of chaulmoogra oil improved, some of them rapidly. The cutaneous lesions in some cases disappeared rapidly under large doses of the oil. Many of these patients, whether treated with chaulmoogra oil or not, seemed to improve; and I made up my mind that the change of climate in coming to New York was largely responsible for some of the improvement, and I think so now. But that chaulmoogra oil was of value I proved to my own satisfaction then, and $I$ think now that it is the only remedy of great value in this disease. I trust that the ethyl esters will be found to be an improved form of administration, but their precise value does not appear to have been fully determined.

One fact that impressed me strongly was that perhaps no other drug has so many different effects, so much unerenness of action on digestion, as chaulmoogra oil. Some patients could not take more than a few drops without intense nausea, while others could take from 100 to 200 drops daily, and those were the ones that improved most rapidly. One patient under my care in New York for twenty years or more always improved temporarily under chanlmoogra oil, but relapses occurred; so I cannot recommend chaulmoogra oil as a specific or a sure cure. Its varied effect on the stomach in different cases, I cannot explain.

There is one other point in the therapentics of leprosy that I would like to mention-the psychic treatment. Many lepers are seized by the health authorities and either sent in a box car back to California or elsewhere, or confined in some shanty with food put through a little window on the end of a stick, while the health officer looks at them with a long face and says, "We will do all we can for you, poor fellow, but you have leprosy." No wonder they get worse. If you and I were treated in such a manner, I think we would rapidly deterioriate in health, and perhaps die, whether we had leprosy or not. My opinion is that many of the patients with leprosy if told that it is not an incurable disease will very likely be relieved in mind and benefited physically, if not entirely cured by this encouragement. I think we can accomplish more this way than by the administration of any drug. As I said, I think the change in climate has much to clo with improvement. For a long time $I$ believed that leprosy was not contagious. Perhaps I would not say so now, but I would still claim that a leper in any community is by no means as serious a menace to public health as is a case of mild tuberculosis. I have known of patients with the nodular form living for thirty years before the disease had gone on to a "fatal termination" in spite of what our textbooks used to state; and if these patients were encouraged with the hope of a cure and not scared to death, I think they would all improve, if not recover.

Dr. Harry G. Irvine, Minneapolis: I should like to ask Dr. Corlett whether in his observation in the Islands he saw any children with leprosy. In this 
regard I should like to relate an interesting experience of my own. We have seen a number of cases in Minneapolis and several in one family starting with a case contracted in Minnesota, so far as we can tell from the history. This woman died with leprosy-I will not say from leprosy-and about a year ago I had an opportunity to examine a daughter, now married and three other children; one was already dead with leprosy. The daughter is just beginning to have thickening of the eyebrows, some loss of hair and three or four nodules. I also examined her husband and two children. At that time there were no signs of the disease in the children, but a few months later her little girl of 3 or 4 years was brought to me for examination. This child then had a peculiar maculopapular eruption, resembling urticaria pigmentosa. It has appeared and disappeared several times, disappearing within a few weeks. and leaving just a little pigmentation. Three months later I saw the child again, and at that time she had three nodules the size of large peas. These were excised and showed all the typical construction of a leprosy nodule. We have never been able to find any bacilli in the nasal secretion or the nodules, but I thought from these findings that the child should be isolated with the mother, at least as a suspect. Both patients were sent to the leprosarium at Carville, La.

Dr. Harry E. Alderson, San Francisco: Dr. Corlett's paper is interesting. and brings up for discussion a subject that is well worth while. Confirming what Dr. George H. Fox said about the beneficial effect of improved hygiene and tonics, I should like to say also that one of the causes of the recent improvement in the matter of the control of lepers in the Islands is the hope that new methods of therapy hold out to the lepers. They feel that there is some chance for them now, and they do not hide away as they formerly did. I have been in Honolulu several times for prolonged visits since 1905 and have been able to observe steady improvement in conditions. An apparent increase in leprosy is believed to have been due to this better cooperation on the part of the natives. More cases are discovered early. On my second visit there I saw a leper who had been hiding away without food, or at least with verylittle, until he was finally apprehended. When brought into the Kalihi Receiving Station he was in poor physical condition, and the leprosy was correspondingly bad. Under proper feeding. baths, strychnin and arsenic, the physical improvement was remarkable. Such experiences are not uncommon. Similar observations have been made by Dr. George H. Fox.

The last time I was in the Hawaiian Islands I was told that it was much easier to get lepers to report. Perhaps one of the greatest benefits of the new treatment is in the encouragement it offers.

Dr. Corlett spoke of the rather "intimate" life in the Islands. Possibly you might be interested in a few of the details. One good old custom in entertaining guests is to have the entire company occupy one large bed spread on the floor. Perhaps a dozen or more may be accommodated in that way. It is common for entire families and sometimes more than one family, to occupy the same bed. One of the popular native dishes, "poi," is made by pounding out the tara root in a large bowl. I have seen natives laboriously pounding out this food in the hot sun, perspiring over it, and even sneezing in it. The final product is a pasty, starchy raw mass, and it is delicious.

The Hawaiian climate is warm and even, except in the mountains. It is like one huge incubator. At times the humidity is quite pronounced. Conditions for the growth and spread of all kinds of bacterial, insect and vegetable life generally are ideal. In more temperate climates where hygiene conditions 
are better, of course the spread of leprosy is necessarily much retarded. In tropical and subtropical countries all of the conditions favorable for the spread of bacterial diseases are present.

Dr. A. W. Stillians, Chicago: Chicago has a small colony of lepers, and we have had an opportunity to try the new form of treatment to some extent. From our experience we feel that the ethyl esters have had a much more rapid effect on the cases than either chaulmoogra oil or Sir Leonard Rogers' sodium gynocardate. Our first patient was under treatment for two years and four months before being discharged as clinically well, and is still receiving treatment every week. Our other patients have been sent to Louisiana because our facilities for treatment are not good, in that we cannot allow the patients any freedom in the open air.

Dr. Thomas Casper GiLchrist, Baltimore: I am glad to see that they are not worrying the patients so much. If patients with syphilis and tuberculosis were worried as those with leprosy are. we would not see those patients as we do. I remember one patient that came to Johns Hopkins and another that came in from Virginia; the latter was almost dying from starvation. I wonder if in Biblical times all diseases of the skin were not called leprosy. Josephus refers to 60,000 cases of leprosy at one time; those cases could not have been leprosy. They were probably cases of itch. I wonder whether scabies, because of the idea of its being contagious, was handed down as leprosy before Hansen found the bacillus, and whether the public has its idea of the great contagiousness associated with scabies and that that might be the explanation of the idea.

I had a case two years ago, a bad nodular case of the face and body, in which I began to administer chaulmoogra oil in small doses. The patient stood it pretty well, and I thought I would try radium and the Kromayer lamp on the nodules on his face to see whether they would disappear more rapidly, and use the chaulmoogra oil on the other lesions. I was delighted to see how quickly the lesions on the face disappeared. When the patient came in, sections were taken and one of the nodules was curetted; in the smear we found the lepra bacilli. The chaulmoogra oil in that case improved the condition very much. The effect of that and cheering and feeding him was remarkable.

Dr. E. L. McEwen, Chicago: I wish to refer to two points. The first concerns the relation of newspaper activity to the persecution of lepers. The first leper to remain any length of time in Cook County Hospital was admitted as a patient with tertiary syphilis. A few hours later a correct diagnosis was made, and the man was placed in a room by himself. A turmoil was expected over the situation, but for some reason. the matter was scarcely referred to by the newspapers; only one conservative evening sheet carried scare-headlines for one issue. As a result of this newspaper quiet the man stayed in the hospital for six weeks, while his deportation was being arranged, entirely without opposition. Since that time a number of lepers have passed through the hospital without a protest. The second point concerns the beneficial effect of simple tonic and hygienic treatment. The extensive, open lesions of the leper to whom I have referred healed completely with six weeks of good food, rest and tonic medication.

Dr. Harvey P. Towite, Boston: I would like to call particular attention to one point brought out by Dr. Corlett, namely, the influence of the universal public fear of the disease on the treatment of the disease and the handling of lepers. As Dr. Gilchrist has said, the public fear of contagion dates back to Bible times and farther and continues today. The effect is reflected in our laws. The leper is legally torn from his family and segregated with his fellow victims 
far from men and amid surroundings which, in any other disease would cause an outburst of horror and indignation from the public. As it is now, the public merely sighs with relief when the leper is hurried away-and forgets him. It is our duty to educate the public to more humane treatment. To accomplish this we must seek exact knowledge of how the disease is spread, its incubation period, and other factors. We who treat leprosy know that in this country it is not as contagious as syphilis or tuberculosis. But, unfortunately, we are unable to convince the public. It therefore seems to me that we should methodically and scientifically gather data concerning the propagation and spread of the disease and seek to give them the widest publicity. Once we have induced the public to regard the leper more humanely and to provide for him, at least as well as for the convict, we shall have increased the potency of our therapeutic remedies immeasurably.

Dr. William Thomas Corlett, Cleveland (closing): Little difficulty is usually experienced in finding the bacillus of Hansen in a lepra lesion. A frequent cite of an early invasion is on the ear. If the ear is punctured and a droplet of blood squeezed out and placed on a slide and treated in the usual way for the acid-fast bacilli, numerous groups or clusters are shown if lepra is present. It is more difficult to find them in macular, particularly in the late macular or atrophic, lesions.

In the intravenous administration of the ethyl esters the initial dose at the Kalihi Hospital is 1 c.c., repeated after a few days or according to the reaction. Naturally, all patients do not tolerate well this form of administration.

In some of the instances, notably the one cited by Dr. Norrow, a small blood vessel is entered even when giving the ethyl esters intramuscularly. This, if the quantity is large, is followed by a severe reaction. I am particularly anxious to add a word on the point brought out by Drs Fox, Gilchrist and Towle, namely, the degree of contagiousness of leprosy, and the apparent immunity enjoyed by some who are exposed to the disease. I have on several occasions, in discussing this disease, cited the testimony of the Sister Superior of the leprosarium in Trinidad, who during a period of thirty-five years had not seen a Sister employed as a nurse contract leprosy. I have always interpreted this as an indication that the disease is, under ordinary circumstances, feebly contagious. More recent experience, however, leads me to believe that cleanliness and aloofness are two of the factors which render the nurse more immune to leprosy than others who live more intimately with those afflicted with the disease. Father Damian may be cited as an example. For if the reports of his life while at Molokai be true, he neglected the ordinary precautions of contact and even of cleanliness. I should ascribe about an equal degree of contagiosity to leprosy and tuberculosis; certain factors of environment and racial susceptibility must be recognized in both diseases.

The Hawaiians seem to be particularly prone to leprosy, and to a less extent to tuberculosis-two causes which are acting in the extermination of the native race on these Islands.

Children are especially likely to contract the disease; the records of the Board of Health at Honolulu show that it is largely a disease of school age, and to the intimate life of children at school is attributed the spread of leprosy in Hawaii.

Several members have mentioned the importance of hygiene in the treatment of leprosy, which I believe, next to complete segregation, is one of the important things to bear in mind in controlling the disease. 